\title{
The Art and Science of Environment and Business in the 21st Century
}

\author{
Melville J. Miranda \\ Australian Education Academy Pty Ltd, Melbourne, Australia
}

\begin{abstract}
Business is a trade or transaction that takes place between two individuals or groups, to achieve a goal or objective. The aim of this paper is to explore the art and science of environment and business in the 21st century, which has an impact on perceptions in a changing business environment. The qualitative method of research is employed and the findings indicate that there is constant innovation to change business.
\end{abstract}

Keywords: business, profit, rapid changes, art and science, perceptions

\section{Introduction}

"Businesses, profit-orientated or otherwise, are going through rapid changes. It is imperative for organizations to keep up with these changes to progress if not to sustain.”

Business has been historically understood as being a trade or transaction that takes place between two individuals or groups, while also being perceived as an activity that enables people to join together as a means of achieving a collective and specific goal or objective. Furthermore, the environment in which business takes place has always been seen as being significant to business outcomes, thus meaning that the elements that play an important role in commerce, such as management, have been defined in numerous ways throughout modern history. As such, the art and science of environment and business in the 21st century will primarily be explored by considering the way in which contemporary world views have impacted current perceptions of how business should be conducted.

\section{Conducting Business in the 21st Century}

The world has experienced a technical revolution, and continues to do so, few would question. Technological progress, especially during the past thirty years, has changed both our world-view and our way of living, as time and distance has become almost a thing of the past. Technical advances, similar to those portrayed in science-fiction films or novels, have revolutionized the life styles of millions of people across the globe and seemingly shrunk our planet. Today, we can shop world-wide; we can work from home to a company on the other side of the world; we can know what is happening throughout the globe almost instantaneously; we can learn, research, and study any given subject through the internet; we can conduct business at an international level, and we can chat with those from different cultures. Modern advancements in satellite technology have meant cell

Melville J. Miranda, Head of Community Welfare, Head of Academic Excellence and Member of Academic Board, Australian Education Academy Pty Ltd. 
phones, international television, mobile technology, and cyberspace-to name just a few. This incredible advancement in technology has meant huge changes in the way we perceive the world and others-apparently helping us to break down misunderstanding and fear of unknown cultures and religions, and, in consequence, leading to what is currently termed as a global village. As such, globalisation has fundamentally changed our planet, especially in relation to the way we now do business.

The art of doing business has always, and still is, fundamentally rooted in gaining financial profit through implementing business practices that are not only productive and proven, but also innovative, fresh, and relevant to the needs of the surrounding society. In other words, business has always been aimed at increasing profits through providing needed and/or wanted products for consumers. However, the art of doing business in today's environment has fundamentally changed due to a number of different factors. Today, for example, people think nothing of surfing the net, completing business transactions on-line, shopping the international market or conducting business with someone on the other side of the globe. We expect to hear news as its taking place in some remote corner of the world, having almost forgotten that in not so distant past communication was often difficult, sometimes impossible. The internet, however, is just one example of how technological advances have completely revolutionized the way we live, and the way in which we conduct business.

In 1970, Europe was as poor as many of today's third-world countries, life expectancy was twenty years shorter, and infant mortality was more than that double. However, due to European and international trade agreements, and the industrial revolution, that all began to change. Thus, by 1950, the European economy had quadrupled, life expectancy had increased, and infant mortality had been reduced by a dramatic $85 \%$. The Europeans were on their way to abolishing poverty. They had globalised the world.

Since World War II, globalisation has been driven by the continuing advances in technology, and the understanding that individual nations can not deal with the planet's problems alone. Degradation of the natural environment, which include examples such as water pollution, over-fishing in the world's oceans, and global warming; the need to deal with international terrorist networks; the parallel objective of implementing world peace; and the mutual benefits that world trade and finance present, have all necessitated the creation of new global institutions.

There has also been tremendous changes in political structures, the end of the Cold War, the tearing down of the Berlin Wall, and the political and economic union of the European Community. Global organizations, such as NATO, the UN and the World Bank, have come into being, and the fight against terrorism is being fought at an international level as world leaders try to steer the world towards peace, tolerance and mutual understanding. In 2002, the Global Scenario Group (GSG), which is an environmental research and forecasting organization, formally presented the results of an extensive study concerning future globalisation in an essay entitled Great transition: The promise and lure of the times ahead. It indicates that "civilization is currently at a turning point, entering a planetary phase of civilization in which different values regarding the environment, human well-being, and global justice might lead to different scenarios for future development” (Raskin, Gallopín, Gutman, Hammond, Robert, \& Swart, 2002). This statement is especially true when considering the complex nature of today's business world. 
In today's contemporary world, societies are demanding that corporations develop practices that are consistent with current thinking and worldviews. This concept, which developed in response to the advancement of technology that has changed commercial markets, demands that firms take responsible action in relation to such changes through acting socially responsible. As such, today's business world is having to constantly adjust their business practices in order to fulfil the expectations of their consumers, stakeholders, and shareholders. Furthermore, it is widely recognized that the only thing that appears to be constant within contemporary business is change, thus meaning that successful businesses are primarily those that are able to consistently manage change. In fact, it is only through doing so that firms are able to hold on to a competitive advantage, thus meaning that business theory has received considerable attention over the past decades.

The impact of globalisation has fundamentally changed world markets, and the way that commerce, in particular corporation giants, conduct business. Change, therefore, is vital for any organization that wishes to progress and sustain in the contemporary world. The majority of major companies, therefore, are attempting to respond to such demands through implementing required changes that will enhance and increase market profits, productivity, customer satisfaction, excellent working conditions, and so forth. As such, managing change has become a significant issue within the business world, while successful businesses tend to be those who are managed by astute business leaders.

Most successful businesses in today's world use a number of different strategies that are constantly being adapted to the constantly changing needs and perceptions of the modern world. Many companies, for example, use market segmentation, an approach which is defined as dividing the market into distinctive categories of consumers that share common characteristics or needs, after which specific categories are chosen to target with an individual marketing mix (Michman, 1991). It is recognized that by effectively serving the public's perceived requirements and needs, the overall success of the company would be assured, thus leading many firms to focus on the demographics and lifestyles of prospective customers, which is based upon the company's perceived vision. For example, the world renown coffeehouse Starbucks, states that its primary objective is to "Establish Starbucks as the premier purveyor of the finest coffee in the world while maintaining our uncompromising principles while we grow" (Starbucks, 2007). These principles are centred on being the most "recognized and the most respected" coffee producer in the business (Ibid.).

Demographic factors include factors such as age, marital status, sex, social status, income and occupation. For example, in accordance with the results of their marketing research, Starbucks targets 18-30 year-olds, both male and female, although it also attempts to cater for other groups. The corporation, therefore, employs publicity that portrays individuals that society considers as being superior, whether through beauty, class, or fashion trends, while the coffee venues themselves are contemporary, inviting, and stylish. People who drink coffee at Starbucks, therefore, are portrayed as being society's cream— the ones who have, apparently, achieved social status.

Starbuck's vision and mission was/is built upon a foundation that has four fundamental concepts: (1) to use only the finest coffee beans, therefore ensuring a reputation of quality; (2) to ensure and maintain a shining reputation in order to guarantee that the name of Starbucks will be remembered by consumers; (3) maintaining a clear set of guidelines pertaining to company policy and staff; and (4) a set of broad goals stating what the 
company could be. Within the third concept, which relates to both management and employees, there are six specific principles that are used as a guideline in order to achieve the company's goals. These are:

- Provide a great work environment and treat each other with respect and dignity;

- Embrace diversity as an essential component in the way they do business;

- Apply the highest standards of excellence to the purchasing, roasting and fresh delivery of their coffee;

- Develop enthusiastically satisfied customers all the time;

- Contribute positively to our communities and the environment;

- Recognize that profitability is essential to... future success (Ibid.).

Through assuring both quality and an optimal working environment, Starbucks has managed to ensure that their product is an essential and positive part of people's daily lives. Their strategy, which has concentrated on reaching potential customers in a variety of different situations, has enabled their product to be available in the workplace, in business, in the home, and when either shopping or dining. Available within grocery stores, department stores, convenience stores, businesses, airports, movie theatres, hotels, homes, and schools, Starbucks has relied upon image advertising in order to promote its products, rather than more traditional methods.

Today, Starbucks is the world's leading coffeehouse company, with more than 13,168 company-owned or licensed stores worldwide in more than forty different countries. Starbucks has gradually increased its products, in accordance with its marketing perceptions, and currently provides a wide range of coffee based drinks, other hot and cold beverages, coffee beans, coffee equipment, mugs, ice creams, and snacks. Through the company's Starbucks Entertainment division and its Hear Music brand, the corporation has also expanded into music, film, and books, while also assuring that many of their brands are available in high street stores (Karp, 1998).

International corporations and businesses in contemporary societies are facing growing demands from various sectors of the community to contribute towards societal and global needs. This, for many corporations, has meant implementing change in order to meet these requirements. In consequence, many companies have established a number of different programmes that are aimed at effectively meeting such demands. Starbucks, for example, is focused on establishing good relationships with coffee farmers. The company states, "the success of the farmers with whom we do business is a critical component of our own success” (Ibid., Starbucks, 2007). This means that the corporation offers their coffee farmers premium prices in order to "help them make profits and support their families," while also enabling them affordable credit "through various loan funds so that farmers can invest in their farms and their success into the future” (Ibid.). In addition, Starbucks has created a Farmer Support Centre, which is located in Costa Rica, and which provides "technical support and training that promotes high-quality coffee for the future” (Ibid.). In addition, Starbucks has also invested in social programs, which "build schools, health clinics, and other projects that benefit the coffee-growing communities" (Ibid.).

Ranked as Fortune No.1 most innovative company within the food industry, Starbucks continues to grow through a marketing strategy that is still founded on its two original concepts which are quality and reputation. The expansion of numerous product lines, such as sodas, ice-reams, etc., has enabled Starbucks to successfully compete against rival organizations, while effectively proving itself an innovative industry leader. The continuation of such marketing tactics continues to enable Starbucks to both maintain customer loyalty while also uphold its image of a company that is widely considered as being one of the most recognized and respected 
international companies within contemporary society. This factor, along with Starbuck's strategy of ensuring that employees share common goals, such as believing in the product that they sell, and their way of ensuring that current policies relate and respect culture and diversity (within all domains), will continue to ensure the international success of this excellent example of effective marketing principles.

The way in which business is constantly changing has caused numerous firms to address the way in which they do business, thus leading to corporation giants such as Cadbury, Schweppes, Wall Mart, and numerous others, to become household names. The art and science of business, therefore, plays a significant role in determining which businesses are going to be successful. For example, McDonald's is one of the world's largest fast-food restaurants, with more than 30,000 outlets serving 52 million people each day in over a hundred different countries. Approximately, 70 percent of the restaurants are independently owned and operated through the McDonald's franchise, but all restaurants sell the same menus, with only a slight variation within different countries. Although famous for a number of items, such as their creamy milkshakes and various different sandwiches, the McDonald's "Big Mac" has been a worldwide favourite since its introduction in 1968. Most importantly, however, is that McDonald's, like Starbucks, was founded on a business strategy that fulfilled customer expectations of its era, and it, like Starbucks, has continued to shape its strategy by implementing change when needed.

The very first McDonald's restaurant was opened by Mac and Dick McDonald in 1940, and their first franchise opened in 1955 in Des Plaines, Illinois, with the motto "Quality”, "Service”, “Cleanliness”, and "Value”, becoming the company’s slogan. By 1963, however, the company was already expanding rapidly. During this year, the one-billionth hamburger was sold, the 500th restaurant was opened, Ronald McDonald made his debut, and the company's net income had exceeded more than \$1 million (mcspotlight.com, 2007a). The company had also become public in 1965. The McDonald’s website states, “a hundred shares of stock costing \$2,250 dollars that day would have multiplied into 74,360 shares today, worth approximately \$3.3 million on December 31, 2006” (mcspotlight.com, 2007b). Currently, McDonald’s shares are sold for around \$60.25.

The "Big Mac” was created by Jim Delligatti in 1968 at Uniontown, Pennsylvania, who owned a McDonald's franchise. Originally, given names such as the "Aristocrat” and "Blue Ribbon Burger”, its final name was conceived by Esther Glickstein Rose, who worked as an advertising secretary in the company's offices in Chicago.

According to publicity, the "Big Mac" sandwich consists of "two all-beef patties, special sauce, lettuce, cheese, pickles, onions, on a sesame seed bun” (Ibid.). However, although these ingredients can be easily purchased, the actual sauce that is used in creating the "Big Mac" has remained a secret since its creation, which means that is difficult create the exact taste of the burger in the home. It is for this reason that people prefer to eat at McDonald's, the author included, because the taste exists nowhere else.

"Neighbourhood marketing” has been identified as the primary reason for McDonald's success. The notion of growing through "one restaurant at a time”, the company has always placed an importance on the idea that "It's all local” (Feltenstein, 2003). Therefore, all restaurants, although being considered as a part of the whole, worked in ways that were conducive with this understanding. Through focusing on the importance of the local outlet, from the bottom to the top, with a major emphasis on the four qualities found within the McDonald's slogan. 
Most successful modern companies, including both Starbucks and McDonald's, were originally constructed on the notions that were current when they were being founded. However, companies such as Starbucks and McDonald's have continued to grow and be successful because of their willingness to adapt and transform in order to meet customer requirements and expectations. For example, both companies were built on slogans and/or mission statements that clearly outlined their purpose and business world view, and both play an active part in local, national, and international communities. As such, both corporations are seen as being socially responsive to world needs, thus enhancing their image.

Another important factor that plays a significant role in determining the successful outcome of a business is the company's management style. Currently, there are three major management theories, including:

(1) Contingency theory

This theory, as suggested by its name, is one that is best described as an approach that is based on the notion of "it depends". In other words, contingency theory supports the idea that management decisions must be made in the light of present circumstances and/or key aspects relating to the current situation. As such, it could be argued that the on-going attempt to identify the optimal management style is moot because it depends on the situation — an individual leading troop in the battlefield, for example, will have a different form of management style than someone in charge of a hospital ward or running a company that makes soft drinks.

(2) Chaos theory

A theory that has only recently emerged, is based on the notion that just like world events can be random and chaotic, so is the world of business. In the past, for example, most managers acted on the notion that organizational events can always be controlled — an idea that included employees. However, today it is broadly acknowledged that business events cannot always be controlled, and that employees should be treated as human beings. Like systems theorists, most chaos theorists pertain to biological systems when describing the theory. They propose that systems become naturally complex. This results in the system becoming increasingly volatile and susceptible to cataclysmic events, creating a need to spend more energy in order to maintain the organization's complexity. As a firm uses more energy, it tends to create more structure to maintain stability, but as this trend continues the system ultimately fails, breaks down entirely, or joins forces with another system. Many advocates of this theory believe that this trend can be found in societies, organizations, and throughout the world, thus suggesting that it is a trend in life.

(3) Systems theory

This approach to management has become increasingly popular among professionals due to the way in which it appears to incorporate so many 21st century concepts and ideologies. Systems theory has significantly influenced management science and the way in which organizations are understood. As suggested by its name, systems theory is rooted in the conception of an organization being a system that involves a number of parts, which must all work successfully together if the business is to thrive. A system is made up of various parts that all work together in order to achieve a common goal. However, if one part of the system is removed or does not function properly, then the system breaks down. For example, a pile of rocks is not a system because if one or several rocks were removed a pile of rocks would still remain a pile of rocks. On the other hand, a functioning vehicle is a system because if you remove one of its parts or if one of the parts failed, the vehicle would no longer 
function properly. Furthermore, a system can be seen as having processes, outcomes, inputs and outputs, and systems collaborate to share feedback from each of these different functions and factors.

However, systems are often complex and multifaceted. Inputs, for instance, would include people, financial resources, raw materials, and technologies. Each of these inputs then follow a process in which they are planned, motivated, organized and controlled in ways that ultimately ensure that the organization's objectives are accomplished. Outputs would include the actual products and services to the company's market, while outcomes would be factors such as productivity, profit, or enhancing the customer's quality of life. Feedback includes customer response, and information given by human resources responsible for implementing the process, but it also includes information obtained from the larger environment of the business, such as local communities, economics, government, and society. Furthermore, this overall framework is a common characteristic of all the systems, including sub-systems such as programs, departments, and so forth within the firm.

Although the systems theory may appear to be basic, and although it is widely acknowledged as being highly successful, it has been only recently that firms have begun implementing it into their business practices due to the tremendous changes caused by factors such as globalisation. As such, it has only been within the past few years that managers and educators have been challenged by this new form of doing business and perceiving the business world. The outcome is the significant paradigm shift in the way business is studied and approached by management science.

Another significant outcome of the influence of systems theory in management is that consultants, educators, scholars, and so forth, are currently enabling managers to approach business from a far broader perspective. In addition, managers now bring a new perspective when interpreting events and patterns within their working environment. For example, many managers recognize the different sectors and aspects of their particular business, and especially the way in which these are interrelated, thus enabling the coordination of its different parts and subsections - supervisors with workers, engineers with manufacturing, central administration with its programs, and so forth. This is an important development because managers no longer tend to study just one aspect of the business and then move on to another, but instead focus on the whole system, which usually results in a far broader synchronization different parts.

\section{Conclusion}

The art and science of environment and business in the 21st century, as this paper has demonstrated, is intrinsically linked. The art of managing a business, for example, is no longer simply a question of implementing the basic functions of management, such as controlling/monitoring, leading/directing, staffing, organizing, and planning, but has instead evolved into a complex and multifaceted process. The managers of Starbucks and McDonalds, for example, have introduced business policy that is aimed at effectively and appropriately meeting the needs/wants and requirements of the surrounding population, of its customers, thus creating an image that takes into account current worldviews. Both firms, therefore, are focused on providing quality, and both have a business vision that is aimed at making them the best in the world. This includes addressing contemporary issues, such as ensuring that the people who provide their products are cared for, being involved in conservationist events, and conducting business in ways that are sustainable. Furthermore, both firms use the system theory of 
management, thus demonstrating their understanding of contemporary issues, while also showing their willingness to both address and change in ways that reflect such understanding. As such, successful firms are those that understand the way in which the art and science of environment and business in the 21st century is essential for long term successful business outcomes.

\section{References}

Feltenstein, T. (2003). McDonald's father knew best: Think "small”; win over the neighbourhood and earn big profits. Retrieved January 10, 2010, from http://findarticles.com/p/articles/mi_m3190/is_5_37/ai_97392578

Karp, H. (1998, February). Worth more than a hill of beans: Vincent eades leads starbucks coffee into the air and beyond. Black Enterprise, 28(7), 78.

Mcspotlight.com. (2007a). McDonalds: A brief history of McDonalds. Retrieved January 10, 2010, from http://www.mcspotlight.org/company/company_history.html

McDonalds.com. (2007b). The McDonald's history. Retrieved January 10, 2010, from http://www.aboutmcdonalds.com/mcd/our_company/mcd_history.html

Michman, R. D. (1991). Lifestyle market segmentation. New York: Praeger Publishers.

Raskin, P. T. B., Gallopín, G., Gutman, P., Hammond, A., Robert, K., \& Swart, R. (2002). Great transition: The promise and lure of the times ahead. A report of the Global Scenario Group. Retrieved January 13, $2010 . \quad$ from http://www.tellus.org/seib/publications/Great_Transitions.pdf

Starbucks. (2007). Official website. Retrieved January 10, 2010, from http://www.starbucks.com/ 